\title{
STATIC AND DYNAMIC FLOW MAPS: COMPARING THE USABILITY BETWEEN IMPAIRED COLOR VISION AND NORMAL COLOR VISION
}

\section{Mapas de fluxo estáticos e dinâmicos: comparando a usabilidade entre a visão impedida de cores e a visão normal de cores}

Fabrício Rosa Amorim ${ }^{1}$ - ORCID: 0000-0002-6670-2131

Edmur Azevedo Pugliesi' - ORCID: 0000-0003-3426-6619

\author{
${ }^{1}$ Universidade Estadual Paulista, Departamento de Cartografia, Presidente Prudente - São Paulo, Brasil. \\ E-mail: fabricioamorimeac@hotmail.com; edmur.pugliesi@unesp.br
}

Received in 07 ${ }^{\text {th }}$ September 2020.

Accepted in $24^{\text {th }}$ September 2021.

\begin{abstract}
:
Flow maps represent data over time that connect different locations. A cartographic representation for different vehicle's flows with color hue variation, ideally, could be well succeed for users having Normal Color Vision (NCV) or having Color Vision Deficiency (CVD). The scientific research about reading flow maps by people having NCV or CVD is not clearly established, mainly when considering the perceptual properties present in the static and dynamic visual variables. This work aims to evaluate and compare the usability (effectiveness, efficiency, and satisfaction) of static and dynamic flow maps reading which were represented by using ordered hues, with 10 people having CVD and with 10 people having NCV. An area located in the city of Presidente Prudente, state of São Paulo, was selected to design eight static maps and eight dynamic maps at 1:5,000 scale. In an experiment conducted in laboratory, the participant's tasks were select and draw routes between origin and destination places shown on maps. The maps were displayed individually in a tablet with a size of 7 inches, and each task lasted up to 30 seconds. The results showed that the efficacy was similar between the NCV and CVD participants when they were using static or dynamic maps. Higher efficiency was found with the use of dynamic maps among participants having NCV, and higher efficiency was found with the use of static maps among participants having CVD. Additionally, dynamic maps showed a higher level of satisfaction than static maps for groups of NCV and CVD. Different kinds of static and dynamic visual variables can be considered as matter of investigation for future research to represent flow of vehicle in the cities, especially for CVD.
\end{abstract}

Keywords: Vehicle Flow Maps; Visual perception; Usability; Static and Dynamic Symbols; Color blindness.

How to cite this article: AMORIM, F.R.; PUGLIESI, E.A. Static and dynamic flow maps: comparing the usability between impaired color vision and normal color vision. Bulletin of Geodetic Sciences. 27(4): e2021029, 2021. 


\section{Introduction}

Flow maps represent the linear movement between different locations by using cartographic language (BERTIN, 1983; SLOCUM et al., 2009; JENNY et al., 2016). To convey more information, they also can be classified. Recommendations to classify choropleth maps can be used to determine the numbers of classes for the flow map (SLOCUM et al., 2009; MUEHLENHAUS, 2014). The visual variable that is suitable to communicate order or differences is transcribed by the visual perception of hierarchy between the flow classes (SLOCUM et al., 2009; HARROWER; BREWER, 2011). The thickness variation of the lines may represent quantitative data (SLOCUM et al., 2009), and the use color dimensions, single or combined, (hue, saturation and value) may represent qualitative or sequential data (SLOCUM et al., 2009; HARROWER; BREWER, 2011). When using a single hue, light shades may represent low values, and dark shades may represent high values.

To represent order with more than one hue, the colors green, yellow, and red (with variations of brightness and saturation) have been used to express different intensities of traffic, such as low, moderate, and intense, respectively (DENT et al., 2009; MUEHLENHAUS, 2014; AMORIM, PUGLIESI, 2017). Google Maps, MapLink, and Waze maps used the monochromatic and polychromatic color schemes to represent traffic flow (PEDROSA et al., 2016; AMORIM, PUGLIESI, 2017). The flow maps do not restrict the representation of movement by using static lines with or arrows or not (to indicate directions). These lines and arrows can be dynamic (MUEHLENHAUS, 2014). If the symbol is moving, the use of the color may facilitate the visual motion perception (DUKACZEWSKI, 2014). Movement allows adding an extra encoding dimension to the information visualization (BARTRAM; WARE, 2002). Therefore, the variable with visual position animation (spatial movement) can be applied to express the phenomenon's displacement.

Johnson and Nelson (1998) evaluated dynamic and static vehicle flow maps which were represented by using the visual variable size. The results showed that dynamic and static maps presented the same effectiveness, although the dynamic maps were more efficiency. However, the design of dynamic map symbols requires distinctive attention (HARROWER, 2004) since it may consider the aspect of the graphic animation variables, as mentioned by Peterson (1995), as well the dynamic variables defined by DiBiase et al. (1992) and MacEachren (1995). Although there is a difference when choosing those variables, its meaning can be understood as similar, and many times used to express its differences in relation to static symbols (HARROWER, 2004).

The detection and discrimination of colors in maps may be problematic for people having Color Vision Deficiency (CVD), commonly known as 'color blindness'. In this sense, the cartographic design should consider detection and discrimination of colors by people visually impaired (MACEACHREN, 2005; CULP, 2012). Although scientific research about the impact of using different visual variables to communicate geographic events by flow maps is not widespread, a good option to cartographically symbolize ordered data is the use of value (MACEACHREN, 1995; EMERY et al., 2021). However, Dobson (1983) pointed that the value as the unique visual variable may result in low performance (effectiveness and efficiency). Value is a visual variable easy to notice, but it may be highly confusing to people with the three types of CVD (deficiency in red, green, and/or blue cones), mainly for the deuteranopes (OLSON; BREWER, 1997).The process of adjustment of colors can promote accessibility in the effective use of maps to the individuals with CVD (OLSON; BREWER, 1997; JENNY; KELSO, 2007a, b; SCHULGA et al., 2019). With this, an accessible map can be created with the choice of suitable colors, considering the individual's perceptive characteristics and the perceptive properties of visual variable (RIBEIRO; GOMES, 2019). Creating a single design with universal color characteristics can help people with and without deficiency in color vision.

During navigation, comprehending some information depicted by color may be a complex task for people with CVD (MACEACHREN, 2005; PUGLIESI; DECANINI, 2011). Thus far, a few studies investigated the most appropriate approaches that use colors for people with normal color vision to represent the directed movement of vehicles on flow maps (JOHNSON; NELSON, 1998; STEPHEN; JENNY, 2017; DONG et al., 2018; YANG et al., 2018). Also, investigations were conducted with people having deficiency in color vision (PEDROSA et al., 2016; AMORIM; 
PUGLIESI, 2017). Studies about the representation of vehicle flow maps that use dynamic symbols and ordered colors are still unknown, especially when considering the color perception between CVD and NCV. For that matter, researchers suggest evaluating the performance of the cartographic communication and the required attention when using dynamic maps compared to static maps (HARROWER, 2007; OPACH et al., 2014).

With the purpose of investigating the visual perception of people having or not having deficiency in color vision through colored cartographic representations, static or dynamic, this research pursued to answer the following questions: "Static or dynamic representations present more usability when perceived by people having or not having deficiency in color vision?"; "The color value as a static visual variable employed in flow lines combined with the position as an dynamic variable employed in point symbols located on the lines result in more precise and efficient detection of order?". Thus, this work aims to evaluate and compare the usability of static and dynamic flow maps which were designed by using ordered hues for route planning, with a group of people having CVD and the other having NCV.

\section{Method}

\subsection{Map design}

To support the task of route selection by people having color vision deficiency or not, a set of static and dynamic maps was designed. The area of study is in the city of Presidente Prudente, in the west region of the state of São Paulo. A database provided by OpenStreetMap (open data and volunteer source for global mapping), dated March 9th, 2017, was used. The scale of 1:50000 was adopted to design the maps, and the cartographic representations were created with the purpose of being displayed on a seven-inch screen (Samsung tablet, model SM, with a resolution of $1024 \times 768$ ). The design of the cartographic representations was organized in two steps.

In the first step, it was designed a set of eight maps which were named by starting with Repr and ending with a number that correspond to a specific map (e.g.: Repr_01; Repr_08). These maps were designed in the ArcGIS software, and they present linear colored symbols to symbolize flow intensities. A layer with different intensities of vehicle flow was designed by considering each street with two ways. Then, the maps were rotated to present streets with two different orientation patterns. The results consist of four maps represented as a rectangular cartesian pattern and four maps represented as an oblique pattern. To create the idea of possible routes between an origin and a destination, four route directions were organized: Route 1 (southeast direction); Route 2 (northeast direction); Route 3 (southwest direction); Route 4 (northwest direction).

In the second step, after saving the maps in image format and point static symbols in arrow format, an overlapping of these symbols was created in the flow maps. This overlapping enhanced the visual perceptions of streetway and flow intensity, resulting in a set of eight static maps. The static point symbols gained linear motion resources to move synchronously over the flow lines to design eight dynamic representations. To produce the static and dynamic symbols that represent the direction and vehicle flow intensity was used Microsoft PowerPoint. From the steps of design and production, 16 cartographic representations were conceived, as eight being static and eight being dynamic. Figure 1 presents the construction order of the eight static maps (STA) and the eight dynamics (DYN), as well as the rotation of the blocks (rectangular cartesian and oblique) and route direction (route 1, route 2, route 3 and, route 4). The maps used in the experiment can be accessed at Amorim (2021). 


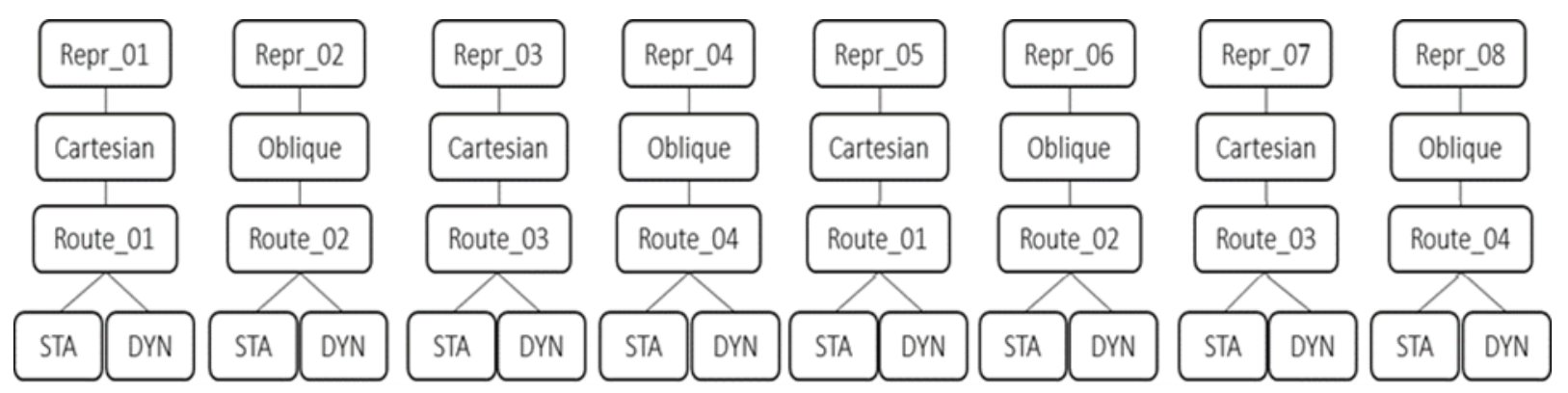

Figure 1: Scheme of cartographic design.

For the conception of the maps were considered the following cartographic data: road network; blocks; crossings; user location (origin); destination; vehicle flow (low, moderate, and intense); road toponymy; road direction and vehicle flow direction. Given the relevance of these features during the selection of a route, it was created two groups: thematic (which includes flow intensity, flow direction (like blocks, road network) and environmental (toponymy).

The flow representation design, including the number of classes, followed the recommendations of choropleth mapping (SLOCUM et al., 2009), aspects of visual perception of order through colors (HARROWER; BREWER, 2011), besides considerations resulting from Google Maps, Waze and MapLink graphs (AMORIM; PUGLIESI, 2017). An overlap of the point symbols that indicate the vehicle flow on lines that indicate the flow intensity was created. The set of eight maps (static) of vehicle flow can be observed in Figure 2 and Figure 3.

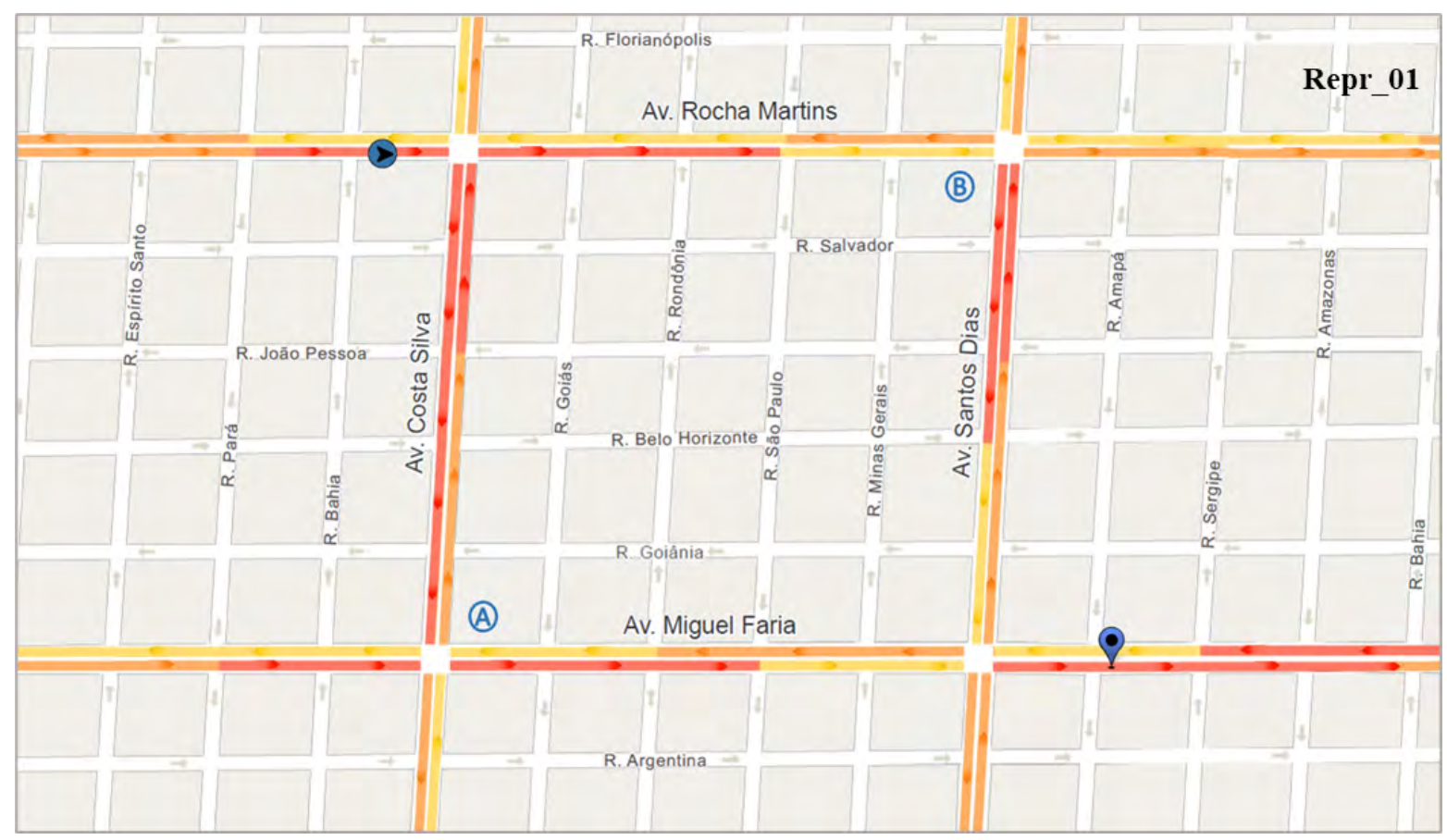

Figure 2: Static vehicle flow map: rotation rectangular cartesian and southeast route direction (Repr_01). 


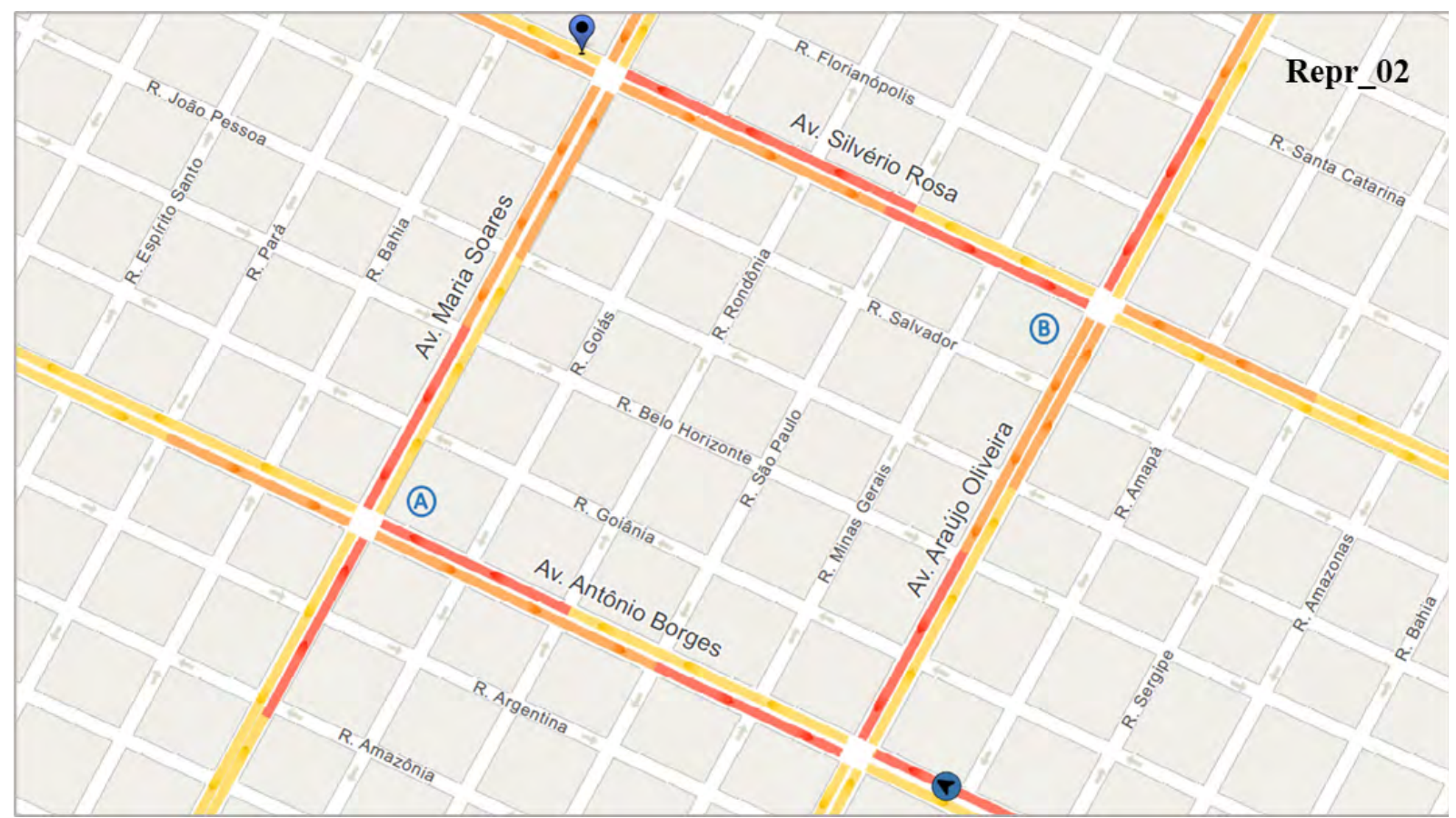

Figure 3: Static vehicle flow map: oblique rotation and northwest route direction (Repr_02).

According to the perceptual capacity of contrast by people with different color vision, it was possible to conceive the classes of vehicle flow. In this step, it was possible to verify the accessibility of the maps through the use of the color vision simulator Color Oracle (OLSON, BREWER, 1997; OLIVEIRA et al., 2014). Figure 4 presents the color simulation to "Repr_01" in the color perception by trichromats and dichromats.
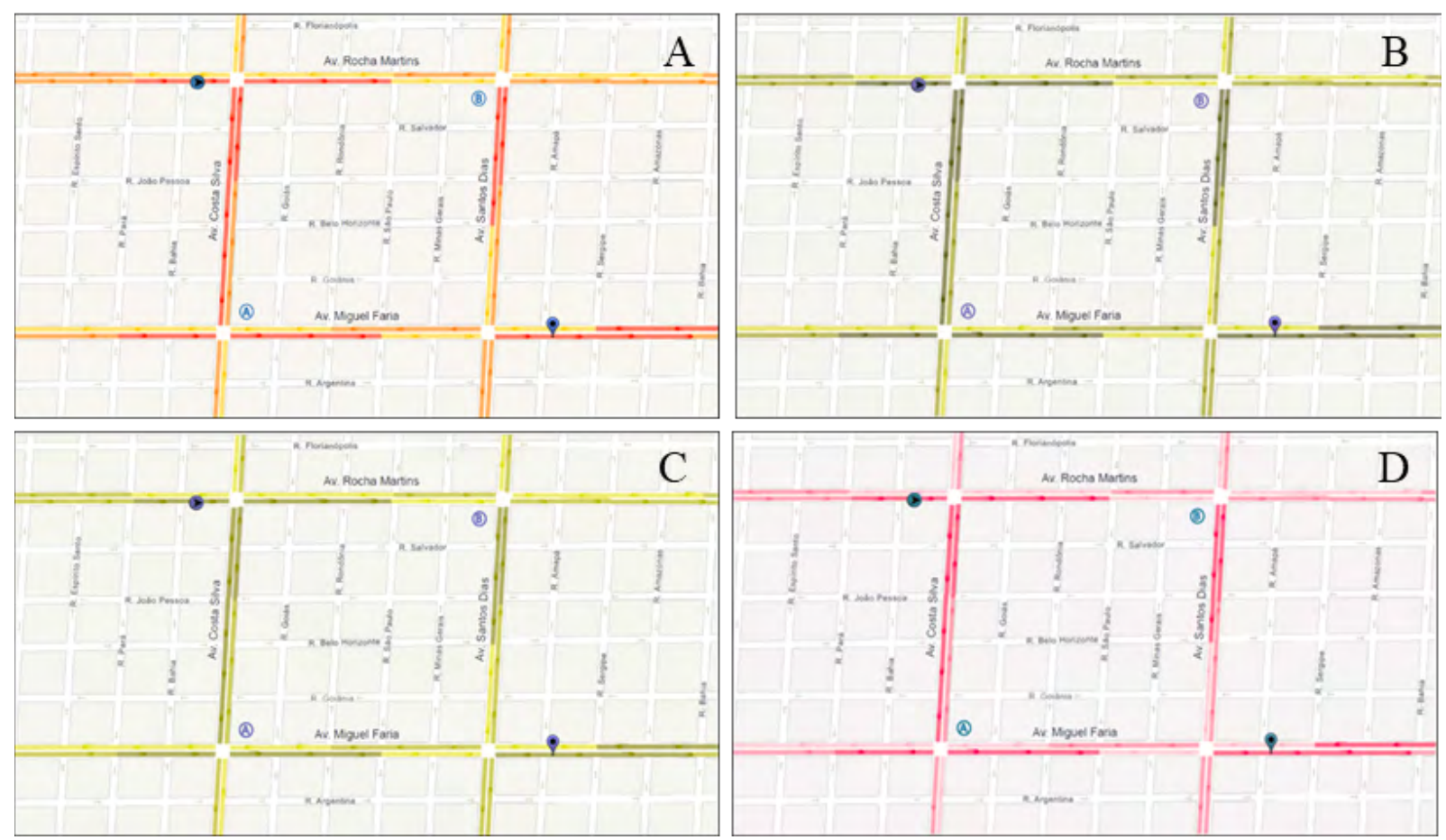

Figure 4: Representation of color perception for Repr_01 by trichromats with NCV (a) and for dichromats para dichromats of type protanope (b), deuteranope (c) e tritanope (d). 


\section{Participants and experiment}

\subsection{Participants}

Personal approach and e-mail promotion, social media, and fixated flyers on the university's walls were a part of the recruitment of the participants. Twenty male participants were selected to participate in the experiments. Two groups divided the participants based on their color vision. The first group was composed of $10 \mathrm{NCV}$ and the second group by $10 \mathrm{CVD}$. From the questionnaire of characterization answered by the participants before the beginning of the experiment, it was possible to obtain data relating to individual and group characteristics. To confirm the participant's characteristics that stated having a deficiency in color vision, the Ishihara test was applied. It tests proved this deficiency for all participants in that group and it was selected after analyzing different types of color vision tests (ZARAZAGA et al., 2019). However, the test was not used to classify participants as to their dysfunctions in color vision.

Due to the incidence of color vision deficiency occurring in $8 \%$ of men and $0.4 \%$ in women (POKORNY et al., 1979; SHARPE et al., 1999), the CVD group was formed by 10 male people, with age above 18 years old and less than 40 years old. Still, this number is due to the difficulty in recruiting participants with visual impairments to carry out experiments (MAIA, 2013; ARAÚJO et al., 2021). The NCV group's age average was 29 years and sampling standard deviation of 6.28 while the CVD group's age average was 27 years old and the sampling standard deviation of 7.46.

Each participant was questioned regarding their general experiences (high, medium, and low) in using maps, in using 'navigation maps' and in using vehicle flow maps (Figure 5). NCV and CVD groups presented similar experiences in using maps, while NCV group presented higher experience on using maps with 'navigations GPS', CVD group assigned lowest level of experience in using vehicle flow maps. Although all the participants stated already using vehicle flow maps, not all of them assigned its interpretation as easily understood. All the participants from the first group that had already used vehicle flow maps stated its understanding as easy. Among the participants from the second group that had already used this type of map, $50 \%$ of them stated to have difficulties in understanding it and those with normal color vision did not have any difficulties.

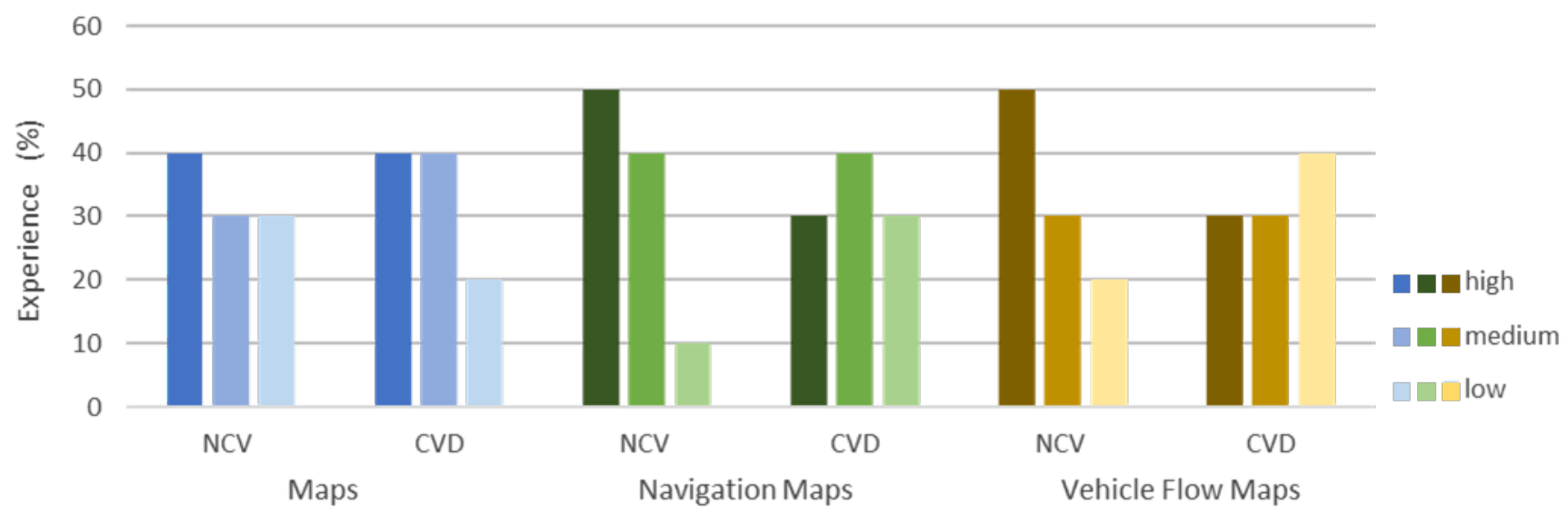

Figure 5: Participant's experience in the use of maps, navigation maps and vehicle flow maps. 


\subsection{Experiment}

The definition of tasks and the selection of the participant's characteristics started the experiment. Colorblind people and people with NCV, used tasks to verify their learning and performance during the route selection, a part of the navigation process. The evaluation of usability (effectiveness, efficiency, and satisfaction level) was used to inspect the visual perception of the static and dynamic symbols (PUGLIESI et al., 2013). The considerations of visual fixation for the analysis of each visual scene based on detection and duration metrics pointed by Krassanakis et al. (2013) supported this evaluation.

The recording of the verbal of the participants through the Tablet's audio system was selected as the method to collect the route selection data. Part of the data was collected through written answers by the participant and/or by the experimenter, as well as in the participant's voice register, through the device of map exhibition. In addition, through the suggestions of Golledge et al. (2000), the learning of a route can be verified by the person's capacity to describe a route with the creation of a special product (through drawings in a printed map) or through the recovered knowledge of working memory. Thus, the procedure adopted in this research required the memorization and resumption of the chosen route.

To move to the destination, the participant should choose a route from its location. In this case, the best route would be the one that would allow the participant to reach the destination more quickly. In other words, the one that would present the less flow intensity. There were only two options of routes, and although the participant had chosen one or the other, in any of them there would be a conversion (maneuver) that crossed the car's lane that comes in the opposite direction. Although it was not expected by the researcher, this was important so it would not compromise possible additional readings that could be considered.

The tasks were to mentally select one of the two routes that departed from the origin and arrived at the destination more quickly and, afterward, notify the experimenter the chosen route ( $\mathrm{A}$ or $\mathrm{B}$ ). The participant had up to 30 seconds to observe the map and choose of the route. After this observation time, a greyish paper map was handed to the participant to draw the route using three pencils with colors related to flow categories represented in the visualized. It was accomplished a total of total of eight different maps (four static and four dynamics) by the selection and drawing task by each participant.

The participant was familiar with the maps, through the presentation of the symbol's manual and two maps that were similar to those that would be found during the experiment. These maps had the purpose of leveling the knowledge on cartographic representation, as well as the procedures used during the experiment. The first type of map would be a static one and the second type of map a dynamic one, or vice-versa, which shows the sequential exhibition of the maps used in the participant's training. The experiments started after this contextualization step and the knowledge of the maps.

During the experiment, the variables time of answer and rate of success were collected. The rate of success involved the right selection of routes and the right drawing of the places and flow intensities. Five participants of each group (according to the type of color vision) read a set of maps (set 01), the other five participants read the other set of maps (set 02). Each set of maps involved four static maps and one dynamic map. This division provided that each map could be analyzed according to its type (static and dynamic) by each group of participants (normal color vision and deficient in color vision). The procedure for carrying out the experiment for this research can be found in Figure 6. 


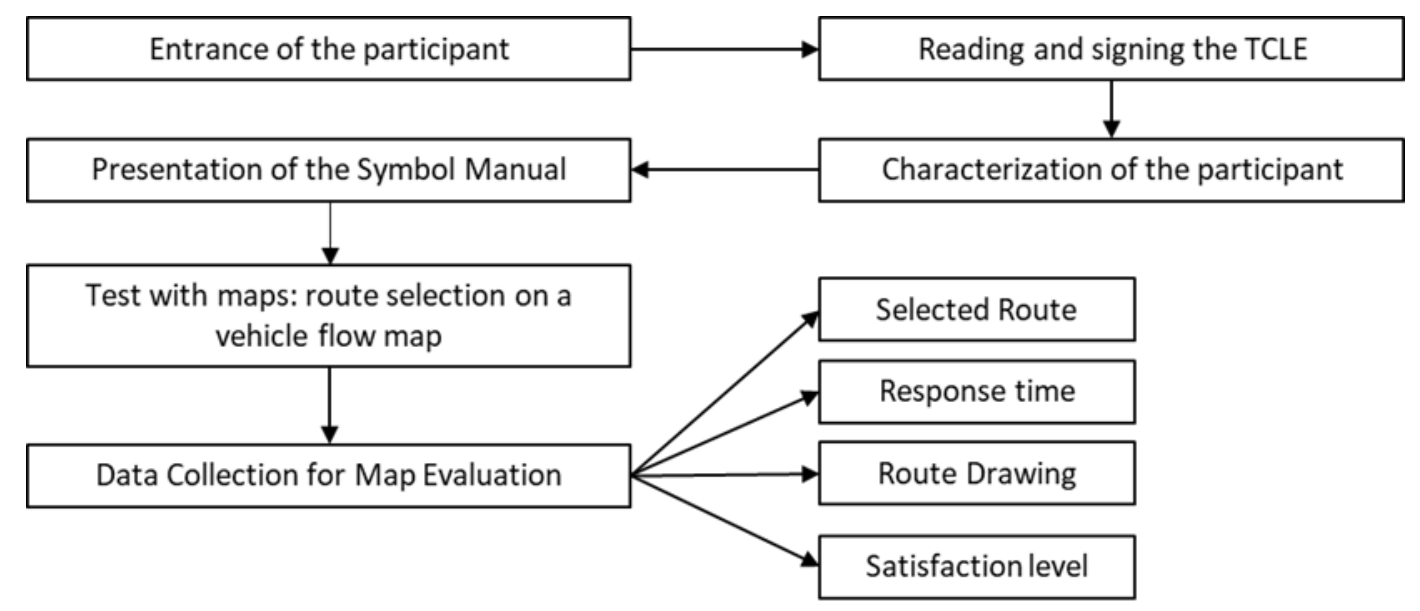

Figure 6: Procedures for carrying out the experiment.

\section{Results and Discussions}

To determine the usability of the designed and produced representations, it was analyzed the following data: time of response to select the route; rate of success to the number of routes correctly selected (route " $\mathrm{A}$ " or route "B"); rate of success for the correct transcription of the vehicle flow along the route (10 parts per route in each map); and satisfaction level by representation type (grade from 0 to 10). To analyze the data collected during the experiments, it was necessary two steps. The first step investigated the performance differences between the participants' groups (NCV versus CDV) and between the types of maps (STA versus DYN). The second step investigated if the different groups of participants presented differences in the performance when reading the different types of maps (NCV-STA versus NCV-DYN; CVD-STA versus CVD-DYN; NCV-STA versus CVD-STA; NCV-DYN versus CVD-DYN).

To do the statistical analysis, it was necessary the software Minitab Pro 18 (student version). The type of statistical analysis utilized (parametric or non-parametric) considered the results from the normality tests about the collected data. It was analyzed, in terms of its distributions (normal or not), through Shapiro-Wilk's test, the values for the data of each group of participants and each type of map. In this normality test, for the significance level of $95 \%$, values of $p$ that are inferior to 0.05 are considered out of the normal distribution. Thus, it defined the hypothesis tests to analyze the set of data.

For the data that presented normal distribution, the hypothesis test selected was the parametric t-Student test (for two depending or independent samples). For the data that did not present normal distribution, the hypothesis test selected was the Mann-Whitney's non-parametric (for two independent samples), as well as the Wilcoxon's non-parametric test (for two dependent samples). The tested hypothesis was: $H_{0}$ : there is no statistically significant difference between the analyzed groups, against $H_{1}$ : there is statistically significant difference between the analyzed groups. With the application of the hypothesis tests, in the case where the value found for $p$ would be inferior or equal 0.05 (with a significance level of 95\%), the null hypothesis would be rejected.

\subsection{Selection of the route}

The analysis in terms of the rate of success in the task of selection of the route to support the determination of the representations' effectiveness uses the set of eight cartographic representations presented to each participant (Figure 7). The calculations considered the correct answers (route A or route B). The route that connects the origin 
and the destination more quickly determined the answers. The ten participants with normal color vision chose a total of eighty routes (one for each cartographic representation): forty for the static maps and forty for the dynamic maps. These values are also applied to the participants with a deficiency in color vision.

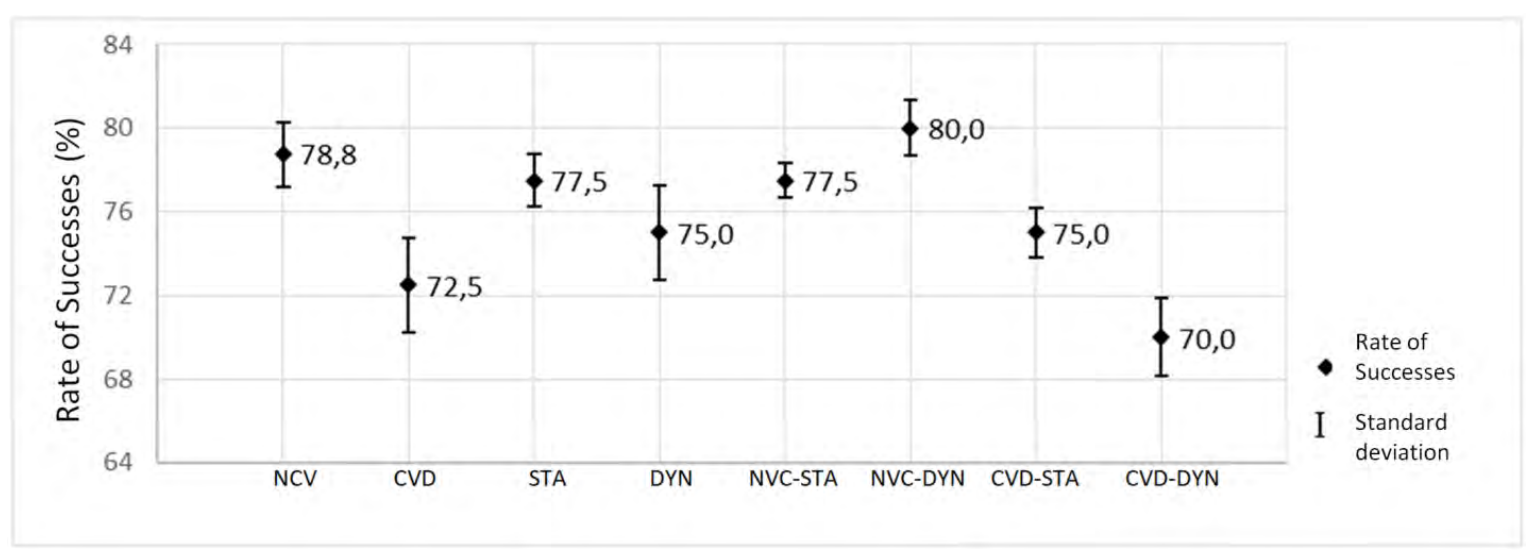

Figure 7: Descriptive statistics for the selection of the route. Caption: NVC $=$ Normal Color Vision; CVD = Color Vision Deficiency; STA = static maps; DYN = dynamic maps.

The descriptive statistics analysis for this task pointed that the participants with NCV obtained a bigger rate of success in this task in comparison to participants with CVD, when considered both types of maps belonging to a set. Participants with NVC were equally effective when reading static maps to dynamic maps, as well as to participants with CVD. When doing the task in dynamic maps, the performance's participants with NVC was superior to the participants with CVD. Still, the participants with CVD were less effective when using dynamic maps. The hypothesis tests (Table 1) realized indicate that there no statistically significant differences between the participants' groups and between the types of maps. Thus, according to the hypothesis test realized, the results are similar to all analyses realized.

Table 1: Hypothesis tests to the selection of the route.

\begin{tabular}{ccc}
\hline Groups analysis & Statistic test & p value \\
\hline NCV versus CVD & t-Student* & 0,360 \\
\hline STA versus DYN & t-Student** & 0,843 \\
\hline NCV_STA versus NCV_DYN & t-Student** & 0,767 \\
\hline CVD_STA versus CVD-DYN & t-Student** & 0,599 \\
\hline NCV_STA versus CVD_STA & t-Student* & 0,796 \\
\hline NCV_DYN versus CVD_DYN & t-Student* & 0,308 \\
\hline
\end{tabular}

* test for two related samples; ${ }^{* *}$ test for two samples that are not related

\subsection{Response time for the task of route selection}

This step comprised the analysis of the response time for the task of route selection. The analysis in terms of rate of the average time for selecting a route for each representation uses eight cartographic representations (Figure 8). This analysis considered all values of time, even for the incorrectly selected routes (route A and route B). The ten participants with normal color vision chose eighty routes from the eight representations: forty for the static maps and forty for the dynamic maps. These numbers were also applied to the participants with a deficiency in color vision. 


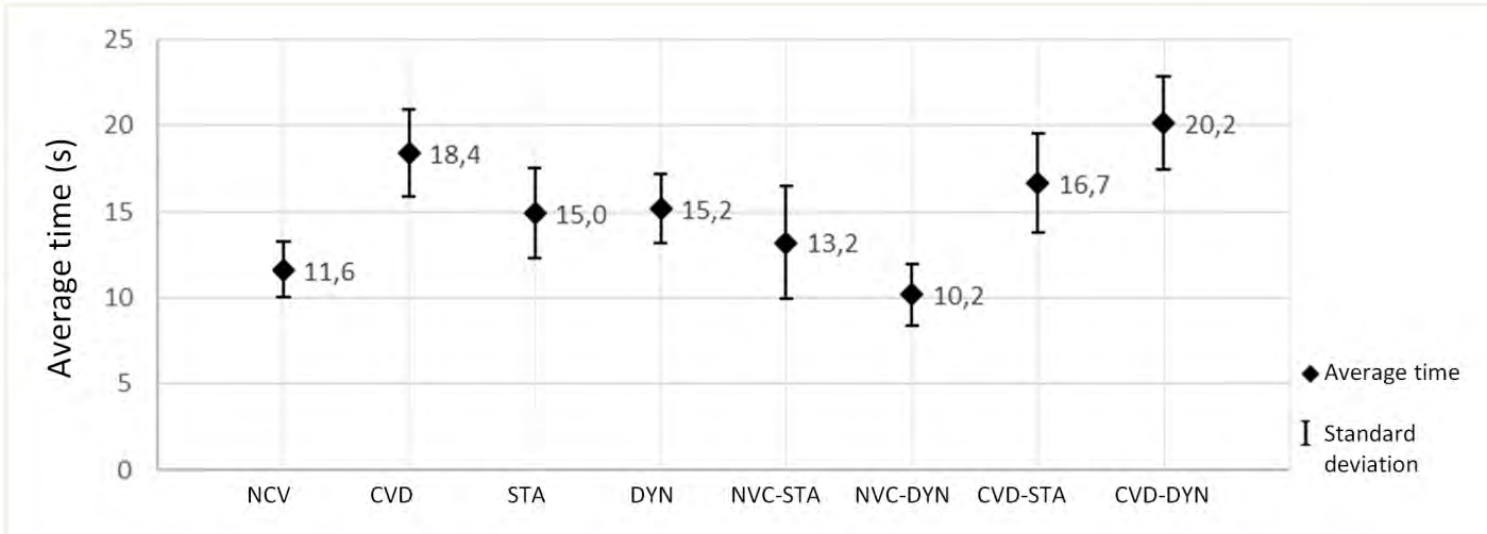

Figure 8: Time for selection of the route. Caption: NVC = Normal Color Vision; CVD = Color Vision Deficiency; STA = static maps; DYN = dynamic maps.

The analysis of the descriptive statistics for this task pointed that the participants with NVC were more efficient than the participants with CVD. Still, this analysis did not indicate that there are expressive differences between the types of maps if it's not considering the visual characteristics of the participants. This result is related to the fact that participants with NVC were more efficient in dynamic maps, while participants with CVD were more efficient in static maps. The results found for the hypothesis tests (Table 2) support the indications that originated from the descriptive statistic for this task.

Table 2: Hypothesis tests for the time for selection of the route.

\begin{tabular}{ccc}
\hline Groups analysis & Statistic test & p value \\
\hline NCV versus CVD & t-Student* & 0,001 \\
\hline STA versus DYN & Wilcoxon** & 0,864 \\
\hline NCV_STA versus NCV_DYN & t-Student** & 0,001 \\
\hline CVD_STA versus CVD-DYN & Wilcoxon* & 0,021 \\
\hline NCV_STA versus CVD_STA & Mann-Whitney** & 0,011 \\
\hline NCV_DYN versus CVD_DYN & t-Student* & 0,001 \\
\hline
\end{tabular}

* test for two related samples; ** test for two samples that are not related

\subsection{Rate of success for the task of drawing of the route}

This step comprised the analysis of the rate of success for the task of drawing of the chosen route, which was composed of 10 segments (adjacent to the blocks' sides) divided into three categories of vehicle flow (low, moderate, and intense). The analysis in terms of the rate of success in this task to determine the efficiency of the representations uses eight cartographic representations presented to each participant (Figure 9). All the drawn routes were considered in this analysis, even the routes that were incorrectly selected (route A or route B). 


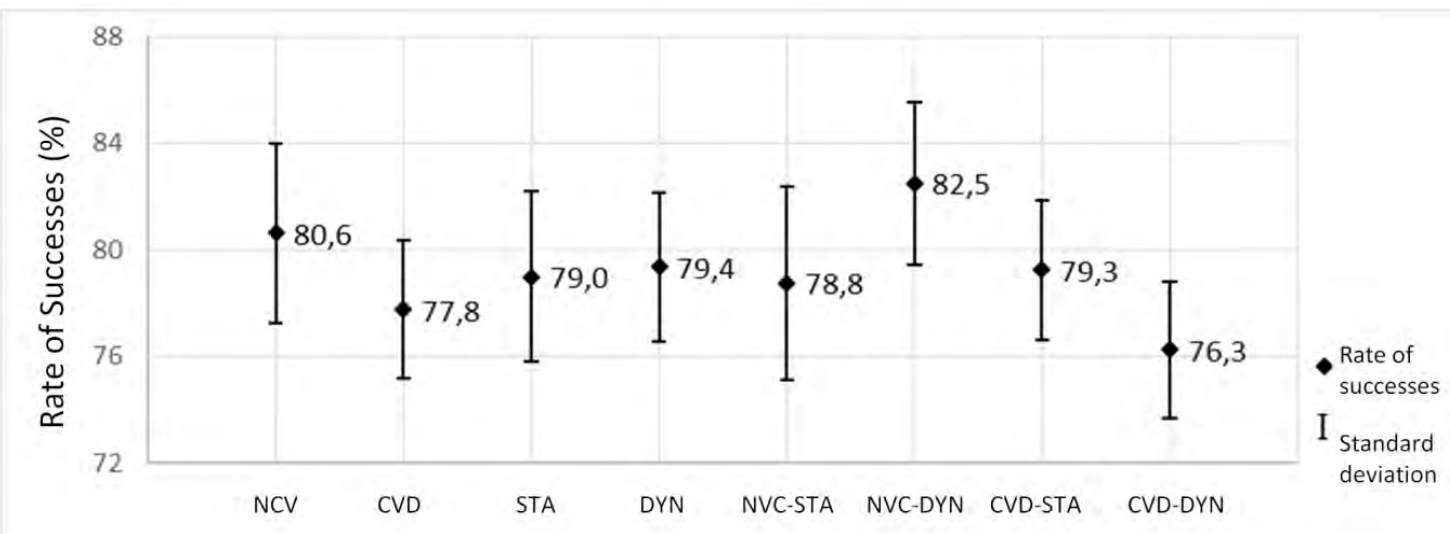

Figure 9: Correct parts of the drawn route. Caption: NVC = Normal Color Vision; CVD = Color Vision Deficiency; STA = static maps; DYN = dynamic maps.

The analysis of the descriptive statistics for this task pointed difference in the performance between the groups of participants, although it did not point difference between the types of maps. This analysis pointed that the participants with NCV were equally efficient when using static or dynamic maps, and the same occurred with participants with CVD. Although, when analyzing the use of dynamic maps, participants with NVC were more effective than participants with CVD. The hypothesis test (Table 3 ) supports the analysis obtained by the descriptive statistics in all analysis in this task.

Table 3: Hypothesis tests for the drawing of the route.

\begin{tabular}{ccc}
\hline Groups analysis & Statistic test & p value \\
\hline NCV versus CVD & Mann-Whitney** & 0,009 \\
\hline STA versus DYN & Wilcoxon* & 0,889 \\
\hline NCV_STA versus NCV_DYN & Wilcoxon* & 0,745 \\
\hline CVD_STA versus CVD-DYN & Wilcoxon* & 0,409 \\
\hline NCV_STA versus CVD_STA & Mann-Whitney** & 0,234 \\
\hline NCV_DYN versus CVD_DYN & Mann-Whitney** & 0,013 \\
\hline
\end{tabular}

* test for two related samples; ** test for two samples that are not related

\subsection{Satisfaction level by types of maps}

This step comprehends the analysis of the satisfaction level by types of maps (static or dynamic). To do so, after the presentation of the maps during the experiment, each participant was assigned grades from 0 to 10 for each type of map. The participants rated each type of map; thus, they received a total of twenty ratings. An analysis of each group of color vision took place considering the satisfaction level by types of (Figure 10). 


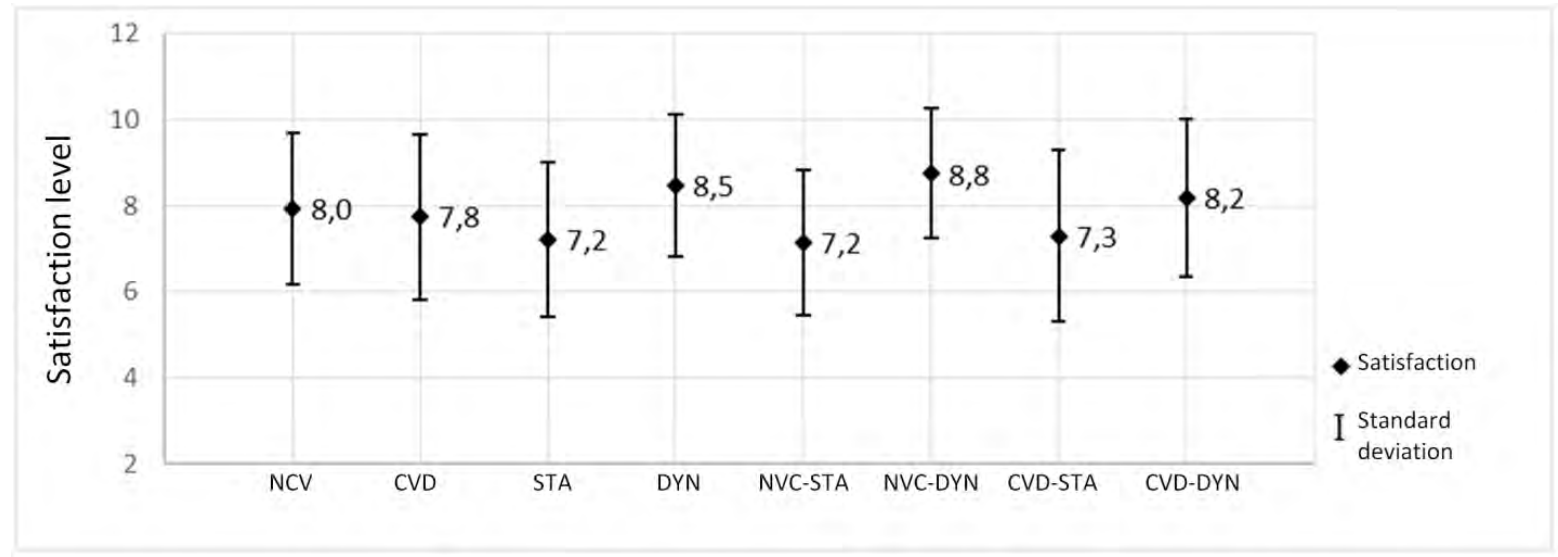

Figure 10: Satisfaction level by types of maps. Caption: NVC = Normal Color Vision; CVD = Color Vision Deficiency; STA = static maps; DYN = dynamic maps.

The analysis of the descriptive statistics for this task did not point to significant differences between the groups of participants when evaluating the map design. Overall, the dynamic map design presented a greater satisfaction level for both groups of participants. The results found for the hypothesis test for this evaluation (Table 4) corroborate with these appointments.

Table 4: Hypothesis tests for satisfaction level by types of maps.

\begin{tabular}{ccc}
\hline Groups analysis & Statistic test & p value \\
\hline NCV versus CVD & Mann-Whitney** & 0,795 \\
\hline STA versus DYN & Wilcoxon* & 0,022 \\
\hline NCV_STA versus NCV_DYN & Wilcoxon* & 0,074 \\
\hline CVD_STA versus CVD-DYN & Wilcoxon* & 0,159 \\
\hline NCV_STA versus CVD_STA & t-Student* & 0,858 \\
\hline NCV_DYN versus CVD_DYN & Mann-Whitney** & 0,416 \\
\hline
\end{tabular}

* test for two related samples; ** test for two samples that are not related

\section{Final Considerations}

This research aimed to investigate how people with NCV and CVD visually perceive colored representations, static or dynamic. To do so, an experiment used static and dynamic maps that represented vehicle flow through colors and direction point. The usability of these maps was analyzed, obtaining results regarding their effectiveness, efficiency, and satisfaction level when read by people with NCV and CVD. In this research, were considered the color perception ordered by multi-hued schemes (when perceived by people with NCV) and single-hue schemes (when perceived by people with CVD) to represent vehicle flow in a street. Although the use of different hues to indicate values can be difficult and confusing, especially for color blinds (BERTIN, 1983; OLSON; BREWER, 1997; MACEACHREN, 2005; SLOCUM et al., 2009), the use of ordered colors (visual variable color value) seemed to be appropriate considering the dichromate and trichromate vision in a single design. For this purpose, the process of the map's color adjustment seems to have promoted accessibility to people with CVD in the effective use of static maps, a fact that confirms that the conclusions from Olson and Brewer (1997) and Jenny e Kelso (2007a; 2007b). 
The experiments showed that people with different types of color vision obtain similar results in terms of effectiveness and efficiency for static maps designed with suitable colors, especially in navigation tasks. In this study were found distinguished benefits in the use of dynamic symbols to retain information of the maps presented to people with different color vision. People with normal color vision tend to be more efficient using dynamic maps, while people with color vision deficiency tend to be more efficient using static maps. The results for effectiveness and efficiency point out the differences in the visual processing of colors and dynamic symbols on maps.

The results of the design and production of maps reached in this research indicate that it is possible to use the selected ordered colors in this work to represent classes of vehicle flow in a suitable way to people with NCV and CVD. However, the results indicated that the design of dynamic symbols in flow maps for people with CVD still needs to be taken care of for the efficiency in reading these symbols to be faster. It is noteworthy that the level of satisfaction for the dynamic maps was bigger for NCV and CVD participants. In general, participants with CVD indicated less distraction and easier to see colors on the static map, while on the dynamic map it was more difficult to perceive the flow color and easier to perceive the direction of the road, in addition to the map being more interesting. Although there is recent research on flow map design and evaluation (STEPHEN; JENNY, 2017; DONG et al., 2018; YANG et al., 2018; REY et al., 2020), it is recommended new studies to evaluate the visual perception of people by other colored and dynamic map symbols. The design and evaluation of vehicle flow map with other static visual variables (e.g.: multi-hued and single-hue, shapes, size) and other dynamic visual variables still lack studies to promote more accessibility for people during the use of navigation maps.

\section{ACKNOLEDGMENTS}

The authors would like to thank the Coordenação de Aperfeiçoamento de Pessoal de Nível Superior (CAPES) for supporting this research under process $n^{\circ} 1582054$.

\section{AUTHOR'S CONTRIBUTION}

All authors contributed equally.

\section{REFERENCES}

AMORIM, F. R. Procedures for Experiments with Volunteers. Available at: http://hdl.handle.net/11449/214050. Accessed in: Aug., 2021.

AMORIM, F. R.; PUGLIESI, E. A. Mapa de fluxo de veículos sob a percepção dos tricromatas e dicromatas In: Anais do XXVII Congresso Brasileiro de Cartografia e XXVI Exposicarta, SBC, Rio de Janeiro - RJ, p. 169-173, 2017.

ARAÚJO, N. S. D., AMORIM, F. R., ANTUNES, A. P., MARCHI, S. R., SCHMIDT, M. A. R., ANDRADE, A. F., \& DELAZARI, L. S. An Experiment Using the Graphic Variable Color and the See Color Code on Isarithmic Maps Accessible to Blind and Normally Sighted People. Boletim de Ciências Geodésicas. 27, 2021.

BARTRAM, L.; WARE, C. Filtering and brushing with motion. Information Visualization, v. 1, n. 1, p. 66-79, 2002.

BERTIN, J. Semiology of Graphics: Diagrams, Networks, Maps. Madison: University of Wisconsin. 415p, 1983. 
CULP, G. M. Increasing Accessibility for Map Readers with Acquired and Inherited Colour Vision Deficiencies. The Cartographic Journal, v. 49, n. 4, p.302-311, 2012.

DENT, B. D.; TORGUSON, J. S.; HODLER, T. W. Cartography: Thematic Map Design. $6^{\circ}$ ed. Dubuque: Wm. C. Brown Publishers, 2009.

DIBIASE, D.; MACEACHREN, A. M.; KRYGIER, J. B.; REEVES C. Animation and the Role of Map Design in Scientific Visualization, Cartography and Geographic Information Systems, p. 201-214, 1992.

DOBSON, J. D. Automated Geography. The Professional Geographer. Volume 35, Issue 2, 1983.

DONG, W.; WANG, S.; CHEN, Y.; MENG, L. Using eye tracking to evaluate the usability of flow maps. ISPRS International Journal of Geo-Information, 7(7), p. 281, 2018.

DUKACZEWSKI, D. R. Designing Simple and Complex Animated Maps for Users from Different Age Groups. Cartography for the Society, Lecture Notes in Geoinformation and Cartography, Springer International Publishing Switzerland, 2014.

EMERY, K. J.; PARTHASARATHY, M. K.; JOYCE, D. S.; WEBSTER, M. A. Color perception and compensation in color deficiencies assessed with hue scaling. Vision Research, 183, p. 1-15, 2021.

GOLLEDGE, R. G.; JACOBSON, R. D.; KITCHIN, M. B. Cognitive Maps, Spatial Abilities, and Human Wayfinding. Geographical Review of Japan Series B. v. 73, n. 2, p. 93-104. 2000.

HARROWER, M. A look at the history and future of animated maps. Cartographica: The International Journal for Geographic Information and Geovisualization, v. 39, n. 3, p. 33-42, 2004.

HARROWER, M., The Cognitive Limits of Animated Maps. Cartographica, p. 349-357, 2007.

HARROWER, M.; BREWER, C. A. ColorBrewer.org: an online tool for selecting colour schemes for maps. The map reader: Theories of mapping practice and cartographic repres., p. 261-268, 2011.

JENNY, B.; KELSO, N. V. Color Design for the Color Vision Impaired. Cartographic Perspectives, 58, p. 61-67, 2007 a.

JENNY, B.; KELSO, N. V. Designing maps for the colour-vision impaired. Bulletin of the Society of Cartographers SoC, 41, p. 9-12, 2007b.

JENNY, B.; STEPHEN, D. M.; MUEHLENHAUS, I.; MARSTON, B. E.; SHARMA, R.; ZHANG, E.; JENNY, H. Design principles for origin-destination flow maps. Cartography and Geographic Information Science, 45(1), 62-75, 2016.

JOHNSON, H.; NELSON E. S. Using Flow Maps to Visualize Time-Series Data: Comparing the Effectiveness of a Paper Map Series, a Computer Map Series, and Animation. Cartographic Perspectives, v. 30, p. 47-64, 1998.

KRASSANAKIS, V. Exploring the map reading process with eye movement analysis. In: Proceedings of the International Workshop on Eye Tracking for Spatial Research, Scarborough, UK. p. 2-5, 2013.

MACEACHAREN, A. M. Visualizing Uncertain Information. Cartographic Perspectives, Guilford Press, 1995.

MACEACHAREN, A. M. How maps work: Representation, Visualization and Design. London: The Guilford Press, 2005.

MAIA, A. F. D. V. M. D. Representação gráfica de mapas para daltônicos: Um estudo de caso dos mapas da rede integrada de transporte de Curitiba. PhD Thesis. Programa de Pós-Graduação em Design - UFPR, 2013.

MUEHLENHAUS, I. Web Cartography - Map Design for Interactive and Mobile Devices, 2014.

OLIVEIRA, R. F.; PUGLIESI, E. A.; RAMOS, A. P. M.; DECANINI, M. M. S. Simulador de Visão de Cores para Aplicação na Cartografia: da Visão Tricromata Normal para a Visão do Daltônico. In: V Simpósio Brasileiro de Ciências Geodésicas e Tecnologias da Geoinformação, 2014.

OLSON, J. M.; BREWER, C. A. An Evaluation of Color Selections to Accommodate Map Users with Color-Vision Impairments. Annals of the Association of American Geographers. Published by: Taylor \& Francis, v. 87, n. 1, p. 103-134, 1997. 
OPACH, T.; GOŁĘBIOWSKA, I.; FABRIKANT, S. I. How do people view multi-component animated maps?. The Cartographic Journal, v. 51, n. 4, p. 330-342, 2014.

PEDROSA, S. N.; PUGLIESI, E. A.; AMORIM, F. R. Percepção de Mapas de Fluxo por Motorista Daltônicos. In: XXVIII Congresso de Iniciação Científica da UNESP, Presidente Prudente. Trabalhos apresentados na $1^{\circ}$ Fase do XXVIII $\mathrm{CIC}, 2016$.

PETERSON, M. P. Interactive and animated cartography. 1.ed. New Jersey: Prentice Hall, 1995.

POKORNY, J.; SMITH, V. C.; VERRIEST, G.; PINCKERS, A. J. L G. Congenital and Acquired Color Vision Defects. Grune and Stratton, New York, 1979.

PUGLIESI, E. A.; DECANINI, M. M. S. Cartographic Design of In-car Route Guidance for Color-Blind Users. In: XXV International Cartographic Conference. Enlightened view on Cartography and GIS, Paris, 2011.

PUGLIESI, E. A.; DECANINI, M. M. S.; RAMOS, A. P. M.; TSUCHIYA, I. Métodos para Avaliação da Usabilidade de Sistemas de Navegação e Guia de Rota. Revista Brasileira de Cartografia. v. 5, n. 65, p. 571-589. 2013.

REY, S.; HAN, S. Y.; KANG, W.; KNAAP, E.; CORTES, R. X. A Visual Analytics System for Space-Time Dynamics of Regional Income Distributions Utilizing Animated Flow Maps and Rank-based Markov Chains. Geographical Analysis, 52(4), p. 537-557, 2020.

RIBEIRO, MADALENA; GOMES A. J. P. Recoloring Algorithms for Color blind People: A Survey. ACM Computing Surveys. v. 52, 4 ed., 37 p., 2019.

SCHULGA, R.; FORREST, D.; HOEY, T. Using a free colour vision simulator to improve the accessibility of orienteering maps. Abstracts of the ICA, v. 1, p. 20, 2019.

SHARPE, L.T.; STOCKMAN, A.; JÄGLE, H.; NATHANS, J. Opsin genes, cone pigments, color vision and color blindness. Color Vision - From genes to perception. Cambridge Press, 1999.

SLOCUM, A. T.; MCMASTER, R. B.; KESSLER, F. C.; HOWARD, H. H. Thematic Cartography and Geovisualization. 3rd ed. Prentice Hall, 2009.

STEPHEN, D. M.; JENNY, B. Automated layout of origin-destination flow maps: US county-to-county migration 20092013. Journal of Maps, 13(1), 46-55, 2017.

ZARAZAGA, A. F., VÁSQUEZ, J. G., \& ROYO, V. P. Revisión de los principales test clínicos para evaluar la visión del color. Archivos de la Sociedad Española de Oftalmología, 94(1), p. 25-32, 2019.

YANG, Y.; DWYER, T.; JENNY, B.; MARRIOTT, K.; CORDEIL, M.; CHEN, H. Origin-destination flow maps in immersive environments. IEEE transactions on visualization and computer graphics, 25(1), 693-703, 2018. 